\title{
COLLEGIATE COACHES' KNOWLEDGE OF THE FEMALE ATHLETE TRIAD IN RELATION TO THEIR CHARACTERISTILS
}

\author{
Jillian E. Frideres, ${ }^{1, A, B, C, D}$ Sue G. Mottinger, ${ }^{2, A, D}$ José M. Palao, A, C, D \\ ${ }^{1}$ Nutrition education program, University of Wisconsin-Extension, Racine, Wisconsin, United States \\ ${ }^{2}$ Department of Health and Kinesiology, The University of Texas Pan American, Edinburg, Texas, United States (retired) \\ ${ }^{3}$ Department of Health, Exercise Science and Sport Management. University of Wisconsin-Parkside, Kenosha, Wisconsin, United States

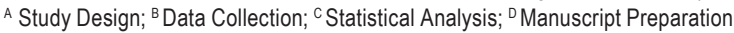

\author{
Address for corpespondence: \\ Jillian E. Frideres \\ 1220 Mound Ave. \\ Racine, WI 53404 United States \\ E-mail: jefrideres@gmail.com
}

\begin{abstract}
Ahstract The purpose of this study was to determine what coaches of female athletes know about the female athlete triad. The sample involved 472 NCAA Division I coaches of female athletes. The variables studied were coaches' knowledge and confidence about the triad and coaches' characteristics (coach's gender, age, type of coach, degree held, years of experience in coaching females, continuing education participation specific to the triad and/or triad components, and sport coached). Coaches' knowledge of the female athlete triad is higher for coaches who have received triad education. No differences regarding knowledge of the female athlete triad were found by gender, degree, experience in coaching female athletes, or coach type. Higher knowledge was found in sports emphasizing low body weight compared to sports that do not emphasize weight. The article discusses the results' implications and the need for future interventions in this population.
\end{abstract}

Key Worlds sport, women, formation, prevention

\section{Introduction}

Coaches play an important role in an athlete's development. They establish the planning and training, create the work environment, and are sources of information as far as training is concerned as well as role models (Field, 1991). It is believed that the coach or staff member that has the best relationship with the athlete may be the bestsuited for communicating with the athlete about any struggles (Eagle, Lohman, Jarman, 2013; Joy et al., 1997b; Nattiv et al., 2007).

Coaches' objectives are to increase their athletes' performances, as well as to shape their athletes as people. Therefore, coaches try to get their athletes to improve the different abilities that affect performance. Additionally, coaches try to prevent injuries among their athletes (by monitoring technique, training load, etc.). Their role in 
regards to injuries is to prevent the situations that are potentially risky, although in performance sport they try to take their athletes to their limits.

For female athletes, a newer health problem has been detected in the last couple decades: the female athlete triad. It is the simultaneous diagnosis of three conditions: disordered eating, amenorrhea, and osteoporosis (Eagle et al., 2013; Hobart, 2000; Nattiv et al., 2007; Otis et al., 1997; Smith, 1996). The general belief in sport, that there is an ideal weight for competing, may increase the pressure on females to be thin (Beals, Brey, Gonyou, 1999). Furthermore, many sports require their female athletes to closely monitor their weight. This may lead to a conscious or unconscious effort on behalf of the athlete to decrease caloric intake and increase energy expenditure and may trigger the process of disordered eating (Nattiv et al., 2007; Sundgot-Borgen, 1994). As a result of a caloric deficit, for some female athletes, menstrual dysfunction occurs, usually in the form of oligomenorrhea (four to nine menstrual cycles per year) or amenorrhea (absence of three or more consecutive cycles after menarche) (TheinNissenbaum, 2013; Otis, Drinkwater, Johnson, Loucks, Wilmore, 1997; Rust, 2002). The absence of normal menses is a serious problem that relates to a reduction in estrogen levels, and, if not attributed to another medical problem, can be a serious consequence of strenuous athletic endeavours. Finally, this decreased estrogen level leads to lower bone mineral density, osteopenia or osteoporosis.

The female athlete triad can involve serious long-term consequences and difficult treatment. Therefore, the importance of early intervention is recognized (Thompson, Gabriel, 2004). However, beyond intervention, prevention is widely regarded as the key to combating the triad (Arendes, Cheung, Barrack, Nattiv, 2012; Beals et al., 1999; Joy, et al., 1997a; Nattiv et al., 2007; Temme , Hoch, 2013; Rust, 2002). Here is where coaches can play an important role. Coaches are a possible key piece in preventive measures, screening, etc. (Eagle et al., 2013; Nattiv et al., 2007; Joy et al., 1997a). The female athlete triad is a relatively new problem; however, many coaches may not be well informed about the triad, though its components are not new. Along these lines, some national governing bodies have considered mandatory education (governing bodies not cited (Joy et al., 1997b)).

The knowledge that coaches have about nutrition and some of the individual components of the triad has been studied, and these studies show that it is not clear whether all coaches are prepared to provide information to their athletes about these topics (Froiland, Koszewski, Hingst, Kopecky, 2004; Jacobson, Sobonya, Ransone, 2001; Juzwiak Ancona-Lopez, 2004; Joy et al., 1997a; Sossin et al., 1997; Pantano, 2006; Troy, Hoch, Stavrakos, 2006). However, few studies have focused on the full triad. Further, most research has focused on specific sports, as this could influence the risk athletes have of suffering the female athlete triad. The effect of a coach's sociodemographic characteristics on this topic is not clear. Pantano (2006) did not find correlations between triad knowledge and gender, coach's education, and/or coaching experience in college coaches.

Sherman et al. (2005), in a study of 2,894 NCAA Division I, II, and III coaches, found that female coaches were more aware of different aspects related to menstruation and talked more with athletes about it than male coaches. Similar results were found by Kroshus et al. (2014) in high school coaches. Women have more positive attitudes and communication behaviours related to eating and menstrual irregularities. No studies have been found about the effect of the years of experience in coaching female athletes, a coach's education (degree), or whether they have received specific training about the triad or the effect of this specific training. The effect of this aspect on the topic is not clear, although, theoretically, with more experience, more education, and specific training, the knowledge of the coaches should be higher. 
In order to contribute to the prevention of the female athlete triad, coaches not only need to know about the three disorders of the triad, how to detect them, and their prevention, but it is also necessary for coaches to have confidence in their knowledge. Without this confidence, the jump from knowledge to application of knowledge is more difficult (Wozney, Venkatesh, Abrami, 2006) or even dangerous, when, without proper knowledge, they can create risky situations. Therefore, the purpose of this study was to determine what coaches of female athletes know about the three components of the female athlete triad and what confidence they have in their knowledge with regard to their socio-demographic characteristics.

\section{Method}

The sample consisted of 472 NCAA Division I coaches of female athletes in the sports of basketball, bowling, cross-country, diving, fencing, field hockey, golf, gymnastics, ice hockey, lacrosse, rifle, rowing, skiing, soccer, softball, swimming, tennis, track and field, volleyball, and water polo. They had an average age of $36.8( \pm 10.1)$ years. Sixty-four percent of participants were female, eighty-nine percent were Caucasian, and fifty-one percent had a master's degree or higher. Forty-eight percent were head coaches, fifty percent were assistant coaches, and two percent were graduate assistants. Participants had $14.5( \pm 9.3)$ years of coaching experience and $13.3( \pm 8.5)$ years of experience of coaching specifically female athletes. All coaches completed the electronic questionnaire after reading an informed consent form that clearly stated that participation in the study was voluntary and data were confidential. The study was approved by the University of Texas-Pan American Institutional Review Board.

An original, self-report questionnaire including multiple-choice questions, categorical questions, and a 4-point Likert scale to measure confidence in answer was used. Questions were designed to ask about the study's variables and the sample's characteristics. The variables were: a) knowledge of the triad, its components, prevention and intervention; b) confidence of the coach in his or her answers; and c) characteristics of the coach (coach's gender, degree held, years of experience in coaching females, continuing education participation specific to the triad and/ or triad components, and sport coached), d) whether coaches provide information and/or educational programming about the female athlete triad; and e) type of continuing education in which they have taken part at least once a year. Finally, questions about the sample's characteristics (ethnicity, number of coaches in their program, etc.) were asked.

From the questions about triad knowledge and confidence of the coaches, an overall knowledge score was calculated which was between 35.00 and -35.00 . The weight of the different parts of the knowledge was: a) identification of triad components, \pm 1 out of 35 ; b) knowledge of triad, \pm 25 out of 35 ; and c) knowledge of prevention and intervention, \pm 9 out of 35 . A correct answer with high confidence obtained a higher score while an incorrect answer with high confidence obtained a lower score.

The process of creating the instrument to measure knowledge of the female athlete triad included three phases. First was the design and development of the instrument, second was the validation of the content, and third was the reliability of the instrument. During instrument design, an expert in online surveys was consulted. The final questionnaire had three parts: a) demographic and experiential questions, b) questions about knowledge of the triad, and c) questions about athletic and team programs.

The design and development of the instrument involved the use of specific literature about the female athlete triad (from World Of Knowledge, SPORTDiscus, Medline, Google Scholar, Sponet, Scielo, and Dialnet databases), questionnaires in the literature that were used as guides (Bradney, 2002; Lassiter, 2002; Martínez-Pecino, 
Mulas-Sánchez, Fernández-Palacín, Bayón-Suárez, 1997; Turk, 1995), and literature about creating an original instrument (Hague, Hague, Morgan, 2004; Thomas, 2004).

For the questions related to knowledge of the triad, an evaluation of the level of confidence of the coach was also included with the answer to measure the coach's specific confidence in the knowledge (Turk, 1995), as a low level of self-confidence has been related to lack of application of the knowledge (Bandura, Wood, 1989). Knowledge and confidence level were taken into account to calculate their overall knowledge score. A correct answer with the highest confidence resulted in the highest weighted score for that question, while an incorrect answer with the highest confidence resulted in the lowest weighted score.

Content was validated by sending the instrument to eight experts in fields related to at least one of the components of the triad for their input and approval. The collective suggestions from the experts were considered, and the appropriate changes were made. Experts in the following fields participated: medicine/family practice, nutrition, physical therapy, eating disorder recovery, triad research in athletes, coaching female athletes, and sport psychology.

The validation of the reliability was done by a pilot study. The questionnaire was sent to select college coaches of an NCAA Division II program from a University that did not participate in the study. The test-retest was completed by 12 coaches. A final section allowing for comments took into consideration their understanding of the questionnaire, the time taken to complete the survey, and questions or concerns they had with the instrument. The pilot study also allowed for technical problems to be worked through. The subjects in the pilot study were not included in data collection for the proposed study. Reliability of each item was calculated using the Kappa Index for each of the questions (categorical variables). Then, the total reliability of the questionnaire was determined by using the smallest of these calculations, and an intra-class correlation coefficient of 0.68 was found.

After the design and the validation of the instrument, the following steps were done: a) the information and e-mails of coaches were obtained, b) the survey was sent to the coaches, c) data were collected, and d) data were analysed.

Subjects for the proposed study were located through the NCAA and university websites. The NCAA website listed institutions with Division I teams in each sport. From there, searches were done at the website of the individual institutions to locate email addresses of subjects. With the sports having a relatively small number of athletes and/ or programs (fewer than 100 programs), an attempt was made to attain the email addresses of as many of these subjects as possible. Therefore, all institutions with these sports were reviewed for each of these sports. While searching for information on these sports, email addresses for coaches from the rest of the sports that were studied were obtained from these institutions. For the sports with fewer than 200 programs, seventy percent of all institutions with swimming and diving programs were randomly chosen and reviewed. Again, email addresses for coaches from the rest of the sports that were studied were obtained from these institutions. Finally, $50 \%$ of remaining institutions (those with more than 300 programs) were randomly chosen and reviewed.

Some institutions did not have athletic information online. Other institutions did not have individual coach contact information available or simply did not provide email addresses. At each institution, all available email addresses of head, assistant, and student coaches in the given sports were collected, though the number that was available varied widely by institution and by sport. Though emails were sent to all coaches whose email addresses were obtained, some emails were rejected by the target server and, therefore, were returned unread. Finally, after questionnaires were completed, data were debugged to remove all incomplete questionnaires. From this process, 
the final sample was determined. The questionnaire was distributed by email to 3,620 coaches, a reminder e-mail was sent after one week, and a thank you and final reminder e-mail was sent after two weeks (deadline). The final sample consisted of 472 subjects for a return rate of $13 \%$. Data were gathered from NCAA Division I coaches during the 2005-2006 academic year.

The relatively low response rate may be the result of various factors. Original letters and reminder letters were sent during the last two weeks of August. Some coaches were not yet in the office, while others were busy with pre-season work. Also, new coaches may not have officially started yet. Finally, it is also possible that some emails went directly into a SPAM mailbox and were never read by the subjects.

A descriptive analysis (means, standard deviations, percentages, and frequencies) and an inferential analysis were done. To test normality, the One-Sample Kolmogorov-Smirnov Test was used. To determine whether there were significant differences among subjects' knowledge of the triad, independent samples t-test and ANOVA were utilized with the test of homogeneity of variances using the Levene statistic. A Scheffe post-hoc test was used if a significant difference was determined from the ANOVA. Significance was set at $p<.05$, and two-tailed testing was used. Data analyses were conducted using the SPSS v.15 (Statistical Package for the Social Sciences; Chicago, IL) software package.

\section{Results}

No significant differences were found in overall score, in any of the sub scores or the confidence in relation to gender of coach, coaches' age, degree held, number of years that they had coached female athletes, or type of coach. Significant differences were found when coaches had received training on the disordered eating component of the triad (Table 1$)$ in their overall score $(p<0.001)$, in the sub scores $(p<0.001)$, and in their confidence $(p<0.001)$.

Significant differences were found between the score of coaches from rowing and cross country with the score of coaches from basketball, softball, and soccer (Table 2). Significant differences were found between the confidence of coaches from track and field and those of soccer.

With relation to the information coaches give the athletes, results showed that a significantly higher number of male coaches ( $16 \%$ more), coaches who were older ( $12 \%$ more), coaches who held a higher degree ( $8 \%$ more), coaches with more experience coaching females ( $11 \%$ more), and head coaches ( $11 \%$ more) were more likely to provide information than their counterparts. The same tendency, although not significant, was found in relation to providing educational programming about the triad (5-10\% more). In all cases, the proportion of coaches that provided information or educational programming about the female athlete triad was less than four out of ten. No significant differences were found in participation in general continuing education for any of the studied variables. Nine out of ten coaches participated in general continuing education. Significantly higher participation in continuing education about the female athlete triad was found by male coaches ( $11 \%$ more), coaches who were older (13\% more), coaches holding a higher degree ( $8 \%$ more), coaches with more experience coaching females ( $13 \%$ more), and head coaches ( $15 \%$ more). In all cases, forty percent or less participated in continuing education about the female triad athlete.

The sources of information that were most used by NCAA coaches to complete their general continuing education were athletic department programs, sport/coaching-related magazines, and textbooks (Table 4). The results show that male coaches $(>20 \%)$, coaches with more experience coaching females ( $18 \%$ more), coaches 
holding a higher degree (19\% more), coaches who were older (16\% more), and head coaches (15\% more) read significantly more professional journals. Female coaches attended significantly more professional conferences (10\% more). Male coaches and older coaches consulted significantly more professionals. Head coaches attended significantly more professional conferences $(10 \%)$ and obtained significantly more information from consulting textbooks ( $10 \%$ more) and other professionals ( $11 \%$ more).

In relation to continuing education about the female athlete triad (Table 4), the sources of information that were most used by NCAA coaches were sport/coaching-related magazines, textbooks, online information, and consulting professionals. The results show that the following sources of information were used significantly more by male coaches: athletic department programs, NCAA-sponsored programs, sport/coaching-related magazines, professional conferences, and consulting professionals. Coaches with more years of experience in coaching females are significantly more likely to read sport/coaching-related magazines. Coaches with higher degrees used the following sources of information significantly more: professional journals, sport/coaching-related magazines, professional conferences, textbooks related to coaching, and consulting professionals. Older coaches were significantly more likely to read professional journals, attend professional conferences, and consult professionals. Head coaches were significantly more likely to read sport/coaching-related magazines and to consult professionals.

Table 1. Triad knowledge and confidence in that knowledge in relationship to coaches' characteristics (data expressed as percentages)

\begin{tabular}{|c|c|c|c|c|c|c|c|}
\hline \multicolumn{5}{|c|}{ Score } & \multicolumn{3}{|c|}{ Confidence } \\
\hline $\begin{array}{c}\text { identify triad } \\
(\%)\end{array}$ & $\begin{array}{c}\text { knowledge } \\
\text { triad }(\%)\end{array}$ & $\begin{array}{c}\text { prevention } \\
\text { intervention } \\
(\%)\end{array}$ & $\begin{array}{l}\text { overall } \\
\text { score }^{1}\end{array}$ & $\begin{array}{c}\text { Score } \\
(\%)\end{array}$ & $p$ & $\%$ & $p$ \\
\hline
\end{tabular}

\begin{tabular}{|c|c|c|c|c|c|c|c|c|}
\hline \multicolumn{9}{|l|}{ Gender } \\
\hline Female & $58.46 \pm 36.58$ & $73.75 \pm 8.35$ & $67.99 \pm 9.42$ & $15.29 \pm 5.32$ & $71.84 \pm 7.60$ & 0.164 & $71.84 \pm 7.60$ & 0.523 \\
\hline Male & $59.68 \pm 37.29$ & $72.09 \pm 7.47$ & $68.61 \pm 9.03$ & $14.59 \pm 4.74$ & $70.84 \pm 6.77$ & & $70.85 \pm 6.77$ & \\
\hline \multicolumn{9}{|l|}{ Age } \\
\hline 22-34 years & $58.61 \pm 36.25$ & $73.48 \pm 8.38$ & $73.73 \pm 8.38$ & $15.22 \pm 5.38$ & $71.74 \pm 7.69$ & 0.106 & $71.09 \pm 7.69$ & 0.986 \\
\hline$>34$ years & $59.24 \pm 37.34$ & $72.52 \pm 7.87$ & $72.52 \pm 7.87$ & $14.79 \pm 4.92$ & $71.13 \pm 7.03$ & & $71.11 \pm 7.03$ & \\
\hline \multicolumn{9}{|l|}{ Degree held } \\
\hline Bachelors & $55.81 \pm 35.98$ & $72.82 \pm 7.62$ & $72.82 \pm 7.62$ & $14.66 \pm 4.83$ & $70.94 \pm 6.90$ & 0.126 & $70.01 \pm 6.89$ & 0.163 \\
\hline Graduate & $62.66 \pm 37.14$ & $73.40 \pm 8.61$ & $73.40 \pm 8.61$ & $15.36 \pm 5.45$ & $71.94 \pm 7.79$ & & $72.08 \pm 7.79$ & \\
\hline \multicolumn{9}{|c|}{ Years coaching } \\
\hline $0-15$ years & $55.99 \pm 36.45$ & $73.21 \pm 8.29$ & $73.21 \pm 8.29$ & $14.94 \pm 5.27$ & $71.34 \pm 7.53$ & 0.716 & $70.52 \pm 7.53$ & 0.250 \\
\hline$>15$ years & $65.58 \pm 36.67$ & $72.97 \pm 7.94$ & $72.97 \pm 7.94$ & $15.16 \pm 4.96$ & $71.66 \pm 7.09$ & & $72.22 \pm 7.08$ & \\
\hline \multicolumn{9}{|l|}{ Type of coach } \\
\hline Head coach & $61.68 \pm 37.09$ & $73.63 \pm 7.83$ & $73.63 \pm 7.83$ & $15.32 \pm 5.00$ & $71.89 \pm 7.14$ & 0.182 & $72.03 \pm 7.14$ & 0.191 \\
\hline Others & $56.17 \pm 36.34$ & $72.63 \pm 8.43$ & $72.63 \pm 8.43$ & $14.68 \pm 5.30$ & $70.97 \pm 7.57$ & & $70.1 \pm 7.57$ & \\
\hline \multicolumn{9}{|l|}{ Triad training $^{2}$} \\
\hline Yes & $60.88 \pm 37.95$ & $74.65 \pm 8.16$ & $74.65 \pm 8.16$ & $17.81 \pm 5.06^{*}$ & $75.44 \pm 7.23$ & $<0.001$ & $78.76 \pm 7.24^{*}$ & $<0.001$ \\
\hline No & $56.62 \pm 35.25$ & $71.34 \pm 7.77$ & $71.34 \pm 7.77$ & $13.94 \pm 4.99^{*}$ & $69.91 \pm 7.13$ & & $68.27 \pm 7.12^{*}$ & \\
\hline
\end{tabular}

Scores for identifying the triad, knowledge of the triad, and prevention and intervention are expressed in percentages; $p=$ level of significance.

${ }^{1}$ Scores obtained for the overall score of female athlete triad knowledge had a range of values between -35.00 and +35.00 .

${ }^{2}$ Training in triad or at least two components of the triad. 
Tahle 2. Triad knowledge and confidence in that knowledge in relationship to coaches' sport

\begin{tabular}{lccccc}
\hline \multirow{2}{*}{ Sport } & $\mathrm{n}$ & \multicolumn{2}{c}{ Overall score $^{1}$} & \multicolumn{2}{c}{ Confidence $^{2}$} \\
\cline { 3 - 6 } & & $\mathrm{M}$ & $\%$ & $\mathrm{M}$ & $\%$ \\
\hline Basketball & 63 & $12.93 \pm 5.31^{*}$ & $68.48 \pm 7.59$ & $2.68 \pm 0.66$ & $3.28 \pm 0.49$ \\
Cross-country & 45 & $18.24 \pm 3.20^{*}$ & $76.07 \pm 4.57$ & $2.97 \pm 0.42$ & $81.97 \pm 12.25$ \\
Diving & 13 & $15.83 \pm 3.75$ & $72.63 \pm 5.36$ & $2.78 \pm 0.71$ & $74.17 \pm 10.44$ \\
Golf & 23 & $15.11 \pm 5.11$ & $71.58 \pm 7.30$ & $3.02 \pm 0.56$ & $69.38 \pm 17.83$ \\
Gymnastics & 15 & $15.43 \pm 5.19$ & $72.04 \pm 7.41$ & $2.72 \pm 0.53$ & $75.62 \pm 13.92$ \\
Lacrosse & 24 & $14.77 \pm 3.79$ & $71.10 \pm 5.41$ & $3.02 \pm 0.69$ & $67.96 \pm 13.25$ \\
Rowing & 39 & $18.62 \pm 5.98^{*}$ & $76.59 \pm 8.54$ & $2.63 \pm 0.63 \ddagger$ & $75.42 \pm 17.35$ \\
Soccer & 53 & $13.27 \pm 4.47^{*}$ & $68.96 \pm 6.39$ & $2.74 \pm 0.57$ & $65.62 \pm 15.78$ \\
Softball & 38 & $13.73 \pm 4.51^{*}$ & $69.62 \pm 6.44$ & $2.88 \pm 0.55$ & $68.57 \pm 14.22$ \\
Swimming & 43 & $15.71 \pm 4.62$ & $72.45 \pm 6.60$ & $2.68 \pm 0.67$ & $71.90 \pm 13.78$ \\
Tennis & 17 & $12.34 \pm 3.65^{*}$ & $67.63 \pm 5.21$ & $3.06 \pm 0.60 \ddagger$ & $66.99 \pm 16.72$ \\
Track \& Field & 75 & $16.70 \pm 4.67$ & $73.85 \pm 6.67$ & $2.88 \pm 0.59$ & $76.48 \pm 14.95$ \\
Volleyball & 41 & $14.88 \pm 5.86$ & $71.26 \pm 8.37$ & $71.97 \pm 14.65$ \\
\hline
\end{tabular}

$p<0.011 ; \neq p<0.009$

${ }^{1}$ Scale from -35 to 35

${ }^{2}$ Scale from 0 to 4 .

Table 3. Providing triad information to athletes and participating in general and triad-specific continuing education in relationship to oaches' characteristics (data expressed as percentages)

\begin{tabular}{lcccccc}
\cline { 2 - 6 } & \multicolumn{2}{c}{ Gender } & \multicolumn{2}{c}{ Age } & \multicolumn{2}{c}{ Degree held } \\
\cline { 2 - 7 } & female & male & $22-34$ yrs & $35-67$ yrs & bachelors & graduate \\
\hline provide information & $18.21^{*}$ & $34.38^{*}$ & $17.17^{*}$ & $30.40^{*}$ & $19.63^{+}$ & $27.97^{+}$ \\
Provide educational prog. & 30.66 & 39.10 & $28.70^{\S}$ & $38.74^{\S}$ & 31.46 & 36.32 \\
General continuing education & 93.27 & 96.34 & 93.70 & 94.02 & 92.53 & 97.65 \\
Triad continuing education & $31.31^{+}$ & $42.68^{+}$ & $28.57^{\S}$ & $41.88^{\S}$ & $41.08^{\S}$ & $49.80^{\varsigma}$ \\
\hline
\end{tabular}

${ }^{1}$ Triad or at least two components of the triad.

Provide information - coach personally provided information about triad; Provide education - provided educational programming about triad; Continuing ed (gen) - participated at least once per year in general continuing education; Continuing ed (triad) - participated at least once per year in triad-specific continuing education.

- level of significance $p<0.001 ;{ }^{+}-$level of significance $p<0.005 ;{ }^{\$}$ - level of significance $p<0.05$.

Table 4. Providing triad information to athletes and participating in general and triad continuing education in relationship to coaches' characteristics (data expressed as percentages).

\begin{tabular}{lcccccc}
\hline & \multicolumn{2}{c}{ Years coaching } & \multicolumn{2}{c}{ Type of coach } & \multicolumn{2}{c}{ Triad training $^{1}$} \\
\cline { 2 - 7 } & $0-15$ yrs & $>15 y r s$ & head coach & other & yes & no \\
\hline Provide information & $19.54^{+}$ & $32.00^{+}$ & $29.33^{+}$ & $18.38^{+}$ & 28.24 & 18.14 \\
Provide educational prog. & 30.69 & 39.73 & 38.01 & 29.57 & 39.44 & 26.50 \\
General continuing education & 94.29 & 93.51 & 95.22 & 92.53 & 97.65 & 95.10 \\
Triad continuing education & $31.75^{+}$ & $44.81^{+}$ & $43.48^{+}$ & $27.39^{+}$ & - & - \\
\hline
\end{tabular}

${ }^{1}$ Triad or at least two components of the triad.

Provide info - coach personally provided information about triad; Provide education - provided educational programming about triad; Continuing ed (gen) - participated at least once per year in general continuing education; Continuing ed (triad) - participated at least once per year in triad-specific continuing education.

- level of significance $p<0.000 ;{ }^{+}-$level of significance $p<0.005 ;{ }^{s}-$ level of significance $p<0.05$. 
Table 5 . Sources of information used by coaches for their general continuing education and triad-specific education in relationship to coaches' characteristics (data expressed as percentages)

\begin{tabular}{|c|c|c|c|c|c|c|}
\hline & \multicolumn{2}{|c|}{ Gender } & \multicolumn{2}{|c|}{ Age } & \multicolumn{2}{|c|}{ Degree held } \\
\hline & female & male & $22-34$ yrs & $35-67$ yrs & bachelors & graduate \\
\hline \multicolumn{7}{|l|}{ General continuing ed. } \\
\hline Athletic Department & 77.78 & 84.15 & 78.15 & 81.62 & 80.97 & 79.25 \\
\hline NCAA-sponsored & 54.88 & 58.54 & 55.46 & 56.41 & 57.52 & 54.36 \\
\hline Journals & $39.73^{*}$ & $61.59^{*}$ & $39.08^{*}$ & $55.98^{*}$ & $42.04^{8}$ & $51.87^{8}$ \\
\hline Magazines & 74.07 & 79.88 & 77.73 & 74.79 & 78.32 & 73.86 \\
\hline Prof. conferences & $70.71^{+}$ & $60.37^{+}$ & 65.55 & 68.38 & 68.14 & 65.56 \\
\hline Textbooks & 66.33 & 72.56 & 66.81 & 69.66 & 65.04 & 72.20 \\
\hline Consult professional & $56.23^{+}$ & $67.07^{+}$ & $55.46^{\&}$ & $64.53^{\&}$ & 60.18 & 59.75 \\
\hline Information online & 58.59 & 56.10 & 61.76 & 53.42 & 58.41 & 56.85 \\
\hline Other & 3.70 & 5.49 & 3.78 & 4.70 & 3.98 & 4.56 \\
\hline \multicolumn{7}{|c|}{ Triad-specific continuing ed. ${ }^{1}$} \\
\hline Athletic Department & $26.67^{+}$ & $35.71^{+}$ & 25.00 & 34.69 & 36.23 & 25.25 \\
\hline NCAA-sponsored & $6.67^{+}$ & $14.29^{+}$ & 8.82 & 10.20 & 7.25 & 11.11 \\
\hline Journals & 33.33 & 32.86 & 27.94 & 35.71 & $24.64^{8}$ & $37.37^{8}$ \\
\hline Magazines & $41.11^{\$}$ & $52.86^{\$}$ & $30.88^{*}$ & $58.16^{*}$ & $37.68^{s}$ & $52.53^{\mathrm{s}}$ \\
\hline Prof. conferences & $8.89^{+}$ & $17.14^{+}$ & $2.94^{\mathrm{s}}$ & $18.37^{\$}$ & $2.90^{\circ}$ & $18.18^{*}$ \\
\hline Textbooks & 44.44 & 42.86 & 38.24 & 50.00 & $37.68^{+}$ & $48.48^{+}$ \\
\hline Consult professional & $60.0^{8}$ & $61.43^{\&}$ & $51.47^{\&}$ & $67.35^{\&}$ & $55.07^{+}$ & $62.63^{+}$ \\
\hline Information online & 44.44 & 41.43 & 50.00 & 38.78 & 47.83 & 39.39 \\
\hline Other & 5.56 & 5.71 & 2.94 & 7.14 & 4.35 & 9.09 \\
\hline
\end{tabular}

${ }^{1}$ Triad or at least two components of the triad.

Continuing ed. (gen) - general continuing education; Continuing ed. (triad) - triad continuing education; Athletic Department - Athletic department programs; NCAA-sponsored - NCAA-sponsored programs; Journals - Professional journals; sport/coaching-related magazines; Prof. conferences - professional conferences; Textbooks - textbooks related to coaching, physiology, nutrition, etc.; Consult prof - Consult professionals; Info online - Information online.

- level of significance $p<0.001 ;{ }^{\$}$ - level of significance $p<0.005 ;{ }^{*}$ - level of significance $p<0.05 ;{ }^{+}-$level of significance $p<0.025$.

Table $\mathfrak{G}$. Sources of information used by coaches for their general continuing education and triad-specific education in relationship to coaches' characteristics (data expressed as percentages)

\begin{tabular}{|c|c|c|c|c|c|c|}
\hline & \multicolumn{2}{|c|}{ Years coaching } & \multicolumn{2}{|c|}{ Type of coach } & \multicolumn{2}{|c|}{ Triad training ${ }^{1}$} \\
\hline & $0-15$ yrs & $>15 \mathrm{yrs}$ & head coach & other & yes & no \\
\hline 1 & 2 & 3 & 4 & 5 & 6 & 7 \\
\hline \multicolumn{7}{|l|}{ General continuing ed. } \\
\hline Ath. department prog. & 79.68 & 79.87 & 81.74 & 78.01 & 83.14 & 80.39 \\
\hline NCAA-sponsored prog. & 54.92 & 57.79 & 59.57 & 52.70 & 57.25 & 57.84 \\
\hline Professional journals & $41.27^{*}$ & $59.09^{*}$ & $55.65^{*}$ & $39.83^{*}$ & $54.51^{\text {s }}$ & $41.67^{\$}$ \\
\hline Magazines & 74.92 & 78.57 & 76.09 & 76.35 & 77.65 & 79.41 \\
\hline Prof. conferences & 65.40 & 70.13 & $72.17^{+}$ & $61.83^{+}$ & 68.24 & 69.12 \\
\hline Textbooks & 66.67 & 70.78 & $73.48^{+}$ & $63.07^{+}$ & 72.55 & 66.67 \\
\hline Consult professional & 56.83 & 65.58 & $65.22^{+}$ & $54.77^{+}$ & $67.06^{\$}$ & $54.90^{5}$ \\
\hline Information online & 59.68 & 53.25 & 56.09 & 58.92 & 58.82 & 59.31 \\
\hline Other & 3.81 & 4.55 & 3.91 & 4.56 & 4.71 & 3.92 \\
\hline
\end{tabular}




\begin{tabular}{|c|c|c|c|c|c|c|}
\hline 1 & 2 & 3 & 4 & 5 & 6 & 7 \\
\hline \multicolumn{7}{|l|}{ Triad continuing ed. ${ }^{1}$} \\
\hline Ath. department prog. & 25.51 & 38.24 & 32.00 & 28.79 & - & - \\
\hline NCAA-sponsored prog. & 9.18 & 10.29 & 10.00 & 9.09 & - & - \\
\hline Professional journals & 30.61 & 35.29 & 33.00 & 31.82 & - & - \\
\hline Magazines & $38.78^{*}$ & $58.82^{*}$ & $53.00^{\&}$ & $37.88^{\&}$ & - & - \\
\hline Prof. conferences & 11.22 & 13.24 & 16.00 & 6.06 & - & - \\
\hline Textbooks & $42.86^{+}$ & $48.53^{+}$ & 49.00 & 39.39 & - & - \\
\hline Consult professional & $56.12^{*}$ & $67.65^{*}$ & $67.00^{\&}$ & $51.52^{8}$ & - & - \\
\hline Information online & 47.96 & 36.76 & 40.00 & 48.48 & - & - \\
\hline Other & 4.08 & 7.35 & 4.00 & 7.58 & - & - \\
\hline
\end{tabular}

${ }^{1}$ Triad or at least two components of the triad.

Continuing ed. (gen) - General continuing education; Continuing ed. (triad) - Triad continuing education; Ath. department prog. -Athletic department programs; NCAA-sponsored prog. - NCAA-sponsored programs; Magazines - sport/coaching-related magazines; Prof. conferences - professional conferences; Textbooks - Textbooks related to coaching, physiology, nutrition, etc.

- level of significance $p<0.001 ;{ }^{\$}$ - level of significance $p<0.005 ;{ }^{\&}$ - level of significance $p<0.05 ;{ }^{+}$- level of significance $p<0.025$.

\section{Discussion}

The purpose of this study was to determine what coaches of female athletes know about the female athlete triad with regard to their socio-demographic characteristics. For overall scores regarding knowledge of the female athlete triad, gender, degree, years of experience in coaching female athletes, and type of coach did not significantly affect the score. However, having training in disordered eating did significantly affect knowledge of the triad.

Specifically, regarding gender, these results show that having more knowledge about menstruation and/or women's health (Sherman et al., 2005; Kroshus, et al., 2014), which theoretically women have, does not result in more knowledge about the triad. Thus, specific training about the triad is needed. These data confirm the results found by Pantano (2006) in college coaches. The same tendency was found in relation to the degree and years of experience, also showing that this type of knowledge is not included in formal education or acquired through experience. The fact that the female athlete triad is a specific issue and relatively new (identified in 1992) may be the cause of this. These data also confirm the results found by Pantano (2006) in college coaches related to degree and years of experience. The reasoning for these results may be that the education of coaches is varied and/or the formation about the female athlete triad is not included in coaches training. These results are different from the tendency of knowledge related to nutrition found by previous studies, which showed a correlation in years of study and coaches' training (Juzwiak, Ancona-Lopez, 2004). The reason is that nutrition is included in coaches' training.

The aspect that correlates with knowledge and confidence in this knowledge is the participation in specific training related to the triad and/or one of its components. These results confirm the importance of coaches' education on having an active role in triad prevention (Eagle et al., 2013; Nattiv et al., 2007). This also shows that without this type of training, coaches lack the knowledge related to prevention and knowing how to act in regard to this health issue. These results showed that specific training is a key aspect in reducing the difference between coaches and medical professionals (Troy et al., 2006). The data that were found reinforce the importance of continuing education for coaches so they can be part of the multidisciplinary team needed to defeat the triad (Nattiv et al., 2007; Temme Hoch, 2013).

Regarding the specific sport (following the sport classification of Rust (2002)), knowledge differences were found between sports that emphasize low body weight (cross-country and rowing) and sports that do not emphasize 
weight (basketball, soccer, and softball). The results show that the type of sport affects the coach's knowledge. The causes may be that coaches are more aware of this problem in their sport, they receive more training, and/or they search for more information. Every sport has its own characteristics, traditions, risks, etc. The female athlete triad is a problem that can affect all female athletes, regardless of their sport, although for some the risk is higher. The results can serve as a reference for designing specific an education program for coaches of the different sports.

Male coaches, head coaches, and coaches who coached females longer have provided athletes with more information. This result could be correlated with the fact that these groups of coaches more likely to participate in continuing education on the subject of the triad. However, the results showed that a low percentage of coaches provide information to their athletes $(<40 \%)$. More studies are needed to know the causes of this low involvement. A possible cause is that coaches do not know or believe the importance of their role in the prevention of the triad or their influence over athletes. This hypothesis is supported partially by the fact that coaches that have a training knowledge provide more information to the athletes, but in a low percentage of cases. The reasoning for this result could be a reduction in confidence because coaches are working with other medical professionals, and they believe that they have different knowledge and skills (Troy et al., 2006). More studies are needed to clarify the reason for the low percentage of communication about this topic and its relation to coaches' knowledge and confidence.

Differences are found in the source of information used by coaches for continuing education in general and for triad education. These differences may be due to the large number of aspects that affect performance and health in sport performance. These differences were found for all the sources of information, except consulting professionals. The differences found related to gender, years of experience, degree, type of coach, and age can serve as a reference for designing and planning coaches' continuing education for athletic departments and/or the NCAA. Specifically, related to female athlete triad education, the most utilized sources by coaches were sport/ coaching-related magazines, textbooks, online information, and consulting professionals.

In general, receiving triad specific education is the aspect that most correlates with knowledge and confidence among NCAA Division I coaches. Specific training and involvement seems to be the key (e.g. coaches of certain types of high-risk sports demonstrate greater knowledge of the triad as well as more confidence in this knowledge). These findings have been suggested previously by other researchers as key for college coaches in relation to managing the triad issue (Heffner et al., 2003; Pantano, 2006; Sherman et al., 2005; Kroshus, et al., 2014). However, inadequate levels of knowledge and information provided to athletes were found.

The female athlete triad is a relatively new issue in coaching. The knowledge of this topic and the aspects that affect it are still unclear. The response rate demonstrated that these coaches may be interested in this topic, which could bias the result (e.g. only coaches interested in this topic answered the survey). The present article provides reference values by type of sport and coaches' characteristics (gender, age, degree held, years coaching, and type of coach) to guide the design and planning of educational training for coaches with regard to coaches' characteristics. The article takes into consideration both knowledge and confidence as criteria for measuring the coaches' knowledge and their possibility of applying it.

\section{Conclusions}

Data found show that coaches' knowledge of the female athlete triad is higher for coaches that have received triad education. No differences regarding knowledge of the female athlete triad were found by gender, degree, years of experience in coaching female athletes, or type of coach. Different triad knowledge was found by different 
type of sport. Higher knowledge was found in sports that emphasize low body weight compared to sports that do not emphasize weight. The data support the idea that specific training about this topic is necessary and useful to increase the knowledge about the female athlete triad, and the sensitization of the coaches about this topic varied according to the type of sport and the emphasis that they place on weight control. Future studies are needed to determine the relationship between coaches' knowledge and coaches' attitudes, communication, and management decisions (Coppola, Ward, Freysinger, 2014; Kroshus, et al., 2014).

\section{Acknowledgements}

We would like to thank all the coaches who completed the survey. Without them, this study would not have been possible.

\section{References}

Arends, J.C., Cheung, M.Y.C., Barrack, M.T., Nattiv, A. (2012). Restoration of menses with non-pharmacologic therapy in college athletes with menstrual disturbances: A 5-year retrospective study. International Journal of Sport Nutrition and Exercise Metabolism, 22 (2), 98-108.

Bandura, A., Wood, R.E. (1989). Effects of perceived controllability and performance standards on self-regulation of complex decisionmaking. Journal of Personality and Social Psychology, 56, 805-814.

Beals, K.A., Brey, R.A., Gonyou, J.B. (1999). Understanding the female athlete triad: Eating disorders, amenorrhea, and osteoporosis. The Journal of School Health, 69 (8), 337-340.

Bradney, D. (2002). Attitudes of coaches regarding eating disorders. Unpublished doctoral dissertation, Springfield College, Springfield, MA.

Coppola, A.M., Ward, R.M., Freysinger, V.J. (2014). Coaches' communication of sport body image: Experiences of female athletes. Journal of Applied Sport Psychology, 26 (1), 1-16.

Eagle, S.R., Lohman, C., Jarman, N. (2013). Enhancing knowledge of nutrition and prevention in medical professionals and coaches; the key to defeating the Female Athlete Triad. Journal of Athletic Medicine, 1 (1), 23-36.

Field, R.W. (1991). Coach as a role model: What are his salient roles and how do others perceive them? Track Technique, 117, 3730-3733.

Froiland, K., Koszewski, W., Hingst, J., Kopecky, L. (2004). Nutritional supplement use among college athletes and their sources of information. International Journal of Sport Nutrition and Exercise Metabolism, 14, 104-120.

Hague, P., Hague, N., Morgan, C. (2004). Market research in practice: A guide to the basics. London, GB: Kogan Page.

Heffner, J.L., Ogles, B.M., Gold, E., Marsden, K., Johnson, M. (2003). Nutrition and eating in female college athletes: A survey of coaches. Eating Disorders, 11, 209-220.

Hobart, J.A. (2000). The female athlete triad. American Family Physician, 61 (11), 3357-3364.

Jacobson, B.H., Sobonya, C., Ransone, J. (2001). Nutrition practice and knowledge of college varsity athletes: A follow-up. Journal of Strength and Conditioning Research, 15, 63-68.

Joy, E., Clark, N., Ireland, M.L., Martire, J., Nattiv, A., Varechok, S. (1997a). Team management of the female athlete triad: Part 1: What to look for, what to ask. The Physician and Sportsmedicine, 25 (3), 94-102.

Joy, E., Clark, N., Ireland, M. L., Martire, J., Nattiv, A., Varechok, S. (1997b). Team management of the female athlete triad: Part 2: Optimal treatment and prevention tactics. The Physician and Sportsmedicine, 25 (4), 55-64.

Juzwiak, C.R., Ancona-Lopez, F. (2004). Evaluation of nutrition knowledge and dietary recommendations by coaches of adolescent Brazilian athletes. Journal of Sport Nutrition and Exercise Metabolism, 14, 222-235.

Kroshus, E., Sherman, R.T., Thompson, R.A., Sossin, K. Austin, S.B. (2014). Gender differences in high school coaches' knowledge, attitudes, and communication about the female athlete triad. Eating Disorders, 22 (3), 1-16.

Lassiter, J.W. (2002). A survey of student coaches' knowledge, attitudes, skills, and behaviors regarding the female athlete triad. Unpublished master's thesis, State University of New York College at Brockport. 
Martínez-Pecino, M., Mulas-Sánchez, M.Y., Fernández-Palacín, F., Bayón-Suárez, F. (1997). Encuesta a los médicos internos residentes de rehabilitación sobre su formación. [Survey to medical residents of rehabilitation about their formation]. Rehabilitación, 31, $17-22$.

Nattiv, A., Loucks, A.B., Manore, M.M., Sanborn, C.F., Sundgot-Borgen, J., Warren, M.P. (2007). American College of Sports Medicine position stand. The female athlete triad. Medicine and Science in Sports and Exercise, 39 (10), 1867-1882.

Otis, C.L., Drinkwater, B., Johnson, M., Loucks, A., Wilmore, J. (1997, May). ACSM position stand: The female athlete triad. Medicine and Science in Sports and Exercise, 29 (5), 1-9.

Pantano, K.J. (2006) Current knowledge, perceptions, and interventions used by collegiate coaches in the US regarding the prevention and treatment of the female athlete triad. North American journal of sports physical therapy: NAJSPT, 1 (4), 195.

Rust, D.M. (2002). The female athlete triad: Disordered eating, amenorrhea, and osteoporosis. The Clearing House, 75 (6), $301-305$.

Sherman, R.T., Thompson, R.A., Dehass, D., Wilfert, M. (2005). NCAA coaches survey: The role of the coach in identifying and managing athletes with disordered eating. Eating Disorders, 13, 447-466.

Smith, A.D. (1996). The female athlete triad: Causes, diagnosis, and treatment. The Physician and Sportsmedicine, 24 (7), $67-73$.

Sossin, K., Gizis, F., Marquart, L.F., Sobal, J. (1997). Nutrition beliefs, attitudes, and resource use of high school wrestling coaches. International Journal of Sport Nutrition, 7, 219-228.

Sundgot-Borgen, J. (1994). Risk and trigger factors for the development of eating disorders in female elite athletes. Medicine and Science in Sports and Exercise, 26 (4), 414-419.

Temme, K.E., Hoch, A.Z. (2013). Recognition and rehabilitation of the female athlete triad/tetrad: A multidisciplinary approach. Current Sports Medicine Reports, 12 (3), 190-199.

Thein-Nissenbaum, J. (2013). Long term consequences of the female athlete triad. Maturitas, 75 (2), 107-112.

Thomas, S.J. (2004). Using web and paper questionnaires for data-based decision making: From design to interpretation of the results. Thousand Oaks, CA: Corwin Press.

Thompson, S.H., Gabriel, M. (2004). Risk factors for the female athlete triad among female collegiate and noncollegiate athletes. Physical Educator, 61 (4), 200-212.

Troy, K., Hoch, A.Z., Stavrakos, J. (2006). Awareness and comfort in treating the female athlete triad: are we failing our athletes? WMJ-MADISON, $105(7), 21$.

Turk, J.C., Prentice, W.E., Chappell, S., Shields, E.W. (1999). Collegiate coaches' knowledge of eating disorders. Journal of Athletic Training, 34 (1), 19-24.

Wozney, L., Venkatesh, V., Abrami, P. (2006). Implementing computer technologies: Teachers' perceptions and practices. Journal of Technology and teacher education, 14 (1), 173-207.

Citethis article aS:. Frideres, J.E., Mottinger, S.G., Palao J.M. (2016). Collegiate Coaches' Knowledge of the Female Athlete Triad in Relation to Their Characteristics. Central European Journal of Sport Sciences and Medicine, 16 (4), 55-66. DOI: 10.18276/cej.2016.4-06. 